\title{
Environmental Assessment of Waste Total Recycling Based on Principles of Logistics and Computer Simulation Design
}

\author{
Martin Straka $^{1 *}$, Samer Khouri², Martin Paška ${ }^{1}$, Michal Buša ${ }^{1}$, Dominik Puškaš ${ }^{1}$ \\ ${ }^{1}$ Institute of Logistics, BERG Faculty, Technical University of Kosice, Kosice, Slovakia \\ ${ }^{2}$ Institute of Earth Resources, BERG Faculty, Technical University of Kosice, Kosice, Slovakia
}

Received: 20 February 2018

Accepted: 26 March 2018

\begin{abstract}
This article deals with total waste separation in the frame of a concrete region in Slovakia. The goal of the contribution is to use logistics, modelling, and simulation for the needs of total waste separation and liquidation to the way raw material and usable sources for new use in practice. Results of the simulation show that by total separation and waste recycling in the frame of the concrete analysed region it is possible to produce during the whole year approximately $390,000 \mathrm{~m}^{3}$ of biogas, and it is possible to obtain approximately $€ 9.3$ million per year, which can be used for developing complex recycling systems in the region.
\end{abstract}

Keywords: total separation, computer simulation, logistics, statistics, assessment

\section{Introduction}

Incinerating waste as a means of waste disposal is very popular not only in Slovakia but throughout the world. If you ask why, we arrive at the definitive answer: "Because it is the easiest way." Burning and transforming bulky elements into ash that can be washed away in water is very simple. The whole operation requires only a box of matches. But Nero's method of solving problems may, in the long term, be inefficient and especially dangerous for the environment.

We are permanently deprived of the valuable source of raw materials. Not being restrictive laws, decrees and regulations on the conditions under which the waste

*e-mail: martin.straka@tuke.sk incineration can be realized in practice, so we should regions full of smoke and smog. The European Union aims as soon as possible to increase the proportion of recycling of waste as a source of secondary raw materials, and waste disposal solutions for incineration were only non-recyclable waste that are suitable as a source of heat and energy.

Recycled plastic composes no hurtful emissions while it is manufactured or while it is being used by the consumer. Plastic spills no toxic chemicals into the water or soil and recycling diminishes pollution. While recycling plastic, it helps to create eco-friendly products and prevents tons of waste from entering our landfills [1-5].

Since the use of plastics is increasing, the new method being considering is recycling. One of the methods is that some of the plastics get mixed in the other materials for recycling; the recycled plastic then 
becomes valuable. Whole plastic material can be used as a binder in the recycling of permeable pavements, which has also been an improvement [1-5].

What is the actual economic dependence and relationship between total recycling and total combustion? What is more profitable?

Of all this shows the question:

- How will the production of gases, ash, and slag from waste incineration?

The aim of this case study is to discuss the use of computer simulation, logistics, and principles of mathematical statistics for the management of total waste separation and waste secondary evaluation processes in the context of environmental protection. No less important is the combination of these three approaches within one cohesive methodological framework to achieve the most efficient waste incineration process within the region of interest, and thus to ensure in practice the long-term sustainable development of the environment.

\section{Theoretical Base}

\section{Logistics, Simulation, and Statistics as Good Performance of Streamlining}

Currently it is not possible to effectively manage material flows nor waste flows without the use and application of principles, methods, and systems of logistics. Logistics is a common word nowadays, since it is an essential component in supply chains and also in the competition of economic operators [6]. Waste processing and disposal and the streamlined processing flows performance can be provided by the means of reverse logistics [7-9]. Reverse logistics stands for all operations related to the collection, remanufacturing, reuse, and recycling of products and materials in the end-of-life phase [10]. It is the process of planning, implementing, and controlling the efficient and costefficient flow of raw materials, in-process inventory, finished goods, and related information from the point of consumption to the point of origin for the purpose of recovering value or proper disposal $[11,12]$. Despite the public appeal and acceptance of recycling, the reverse logistics channels used in recycling have received minimal attention. However, the reverse channels' membership and capabilities have a significant impact on the efficiency of processing recyclable material for remanufacture into recycled products [13]. The main objective of logistic activities within waste management on site concerning the disposal processes is their effective and especially efficient design with respect to ecological, economic, social, and technological goals [14-16]. The importance of reverse logistics increases along with the world's population expansion [17-21], which causes a proportional increase in the amount of generated waste that needs to be processed. According to Fleischmann et al. [22], the management of return flows induced by the various forms of the reuse of products and materials in industrial production processes has received growing attention. Logistics and supply chain management are areas of critical importance for the successful energetic utilization of waste biomass [23-25]. Logistics can be an indispensable part of integrated environmental management programs because of its crossfunctional nature. Logistics provides an overview of environmentally responsible logistics activities and their implications for corporate management. Also examines logistics functions in the context of the corporate value chain and identifies various environmental decision points [26-27].

Tan et al. [28] studied the optimal processing network for municipal solid waste management in Iskandar, Malaysia. In this paper, a mathematical programming model included integration of four principal consuming technologies that has been presented to facilitate the optimal processing of the network. According to the authors Chang and Chang [29], an operational program in a solid waste management system should be based not only on the cost-saving principle but also the energy and material recovery requirements. However, the rising prices of raw materials and the concerns of energy conservation have resulted in an increasing interest in the recovery of materials from the waste streams prior to the incineration facilities. One of the recent issues in the operational program of solid waste incinerators is how to handle the impacts due to different waste streams generated with differing heating values and recyclables content in order to meet the goals of energy recovery, material recycling, and throughput level. Their arguments prove by mathematical modelling reviewing the system of waste treatment. Many authors in different parts of the world face similar challenges to the effective treatment of waste with the help of modelling and simulation [30-36]. Data resulting from modelling and simulation is necessary to analyse and verify their veracity and relevance.

The next possibility for impacts of waste total recycling solution is the application of mathematical modelling [37-39]. Gaussian least squares method is one of the basic methods for data processing. So-called theoretical regression, the relationship of one value to another, or the dependence of one variable (dependent) to another variable (independent), can be obtained from the currently measured, observed data, values pairs $x_{i}$, $y_{i}$, arranged for $V\left\{x_{i}, y_{i}\right\} n$. Regression analysis is a very popular, effective, and applicable tool for identifying dependencies between the examined variables. The advantage of this method is its versatility, considering it makes it possible to calculate the most appropriate parameter values $[40,41]$.

\section{Design of the Waste Total Separation Computer Simulation Model}

To build a comprehensive simulation model of total separation process waste within a particular region in 
Slovakia is necessary in order to prepare and carry out a thorough analysis of the operation of the proposed system, the company for total separation and also follow the parameters of individual processes for the assessment of separated waste.

From the system to analyse the activity of the processing undertaking under the following findings:
- Every year, in the company imported 83000 tons of waste, which passes several levels of processing.

- The first treatment is focused on the separation of plastics, electrical components and wood from imported waste.

- The second phase takes place in the processing of waste incineration and just after the burn.

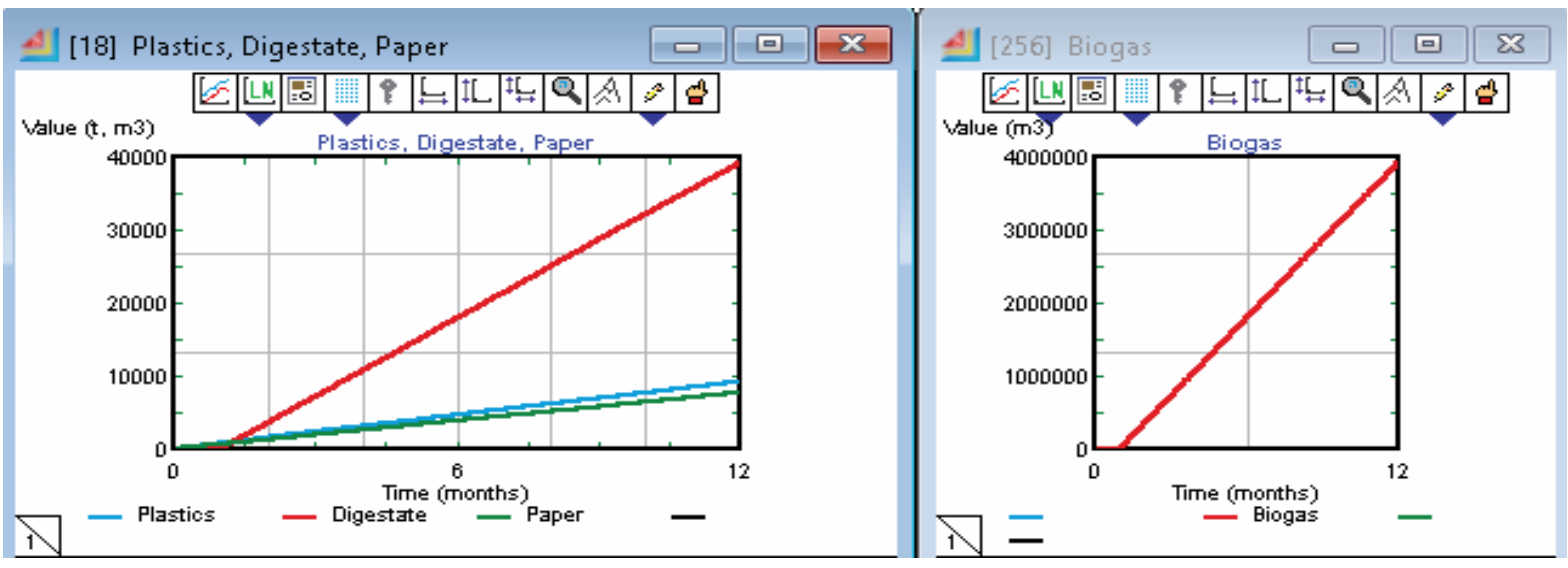

Fig. 1. Production of recycled plastics granules, papers, digestate manor, and biogas from the separated waste in a one-year period.

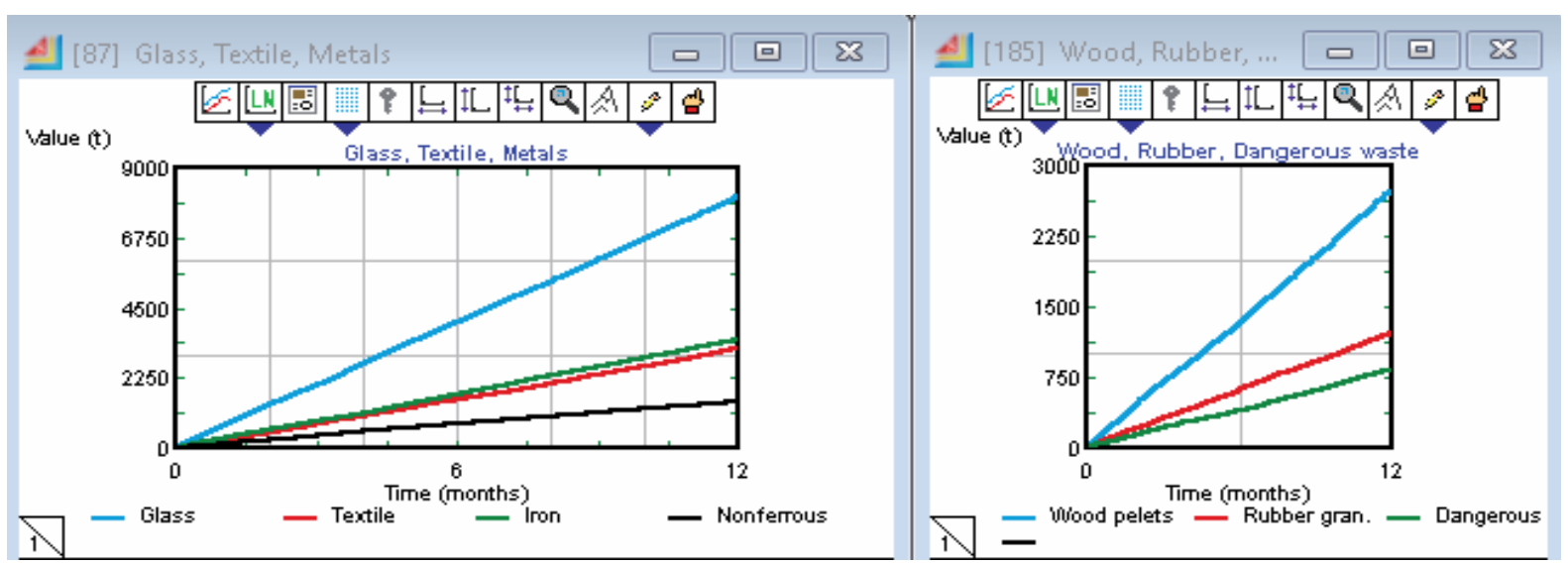

Fig. 2. Production of recycled glass, textile, metals, wood, rubber, and dangerous waste from the separated waste in one-year period.

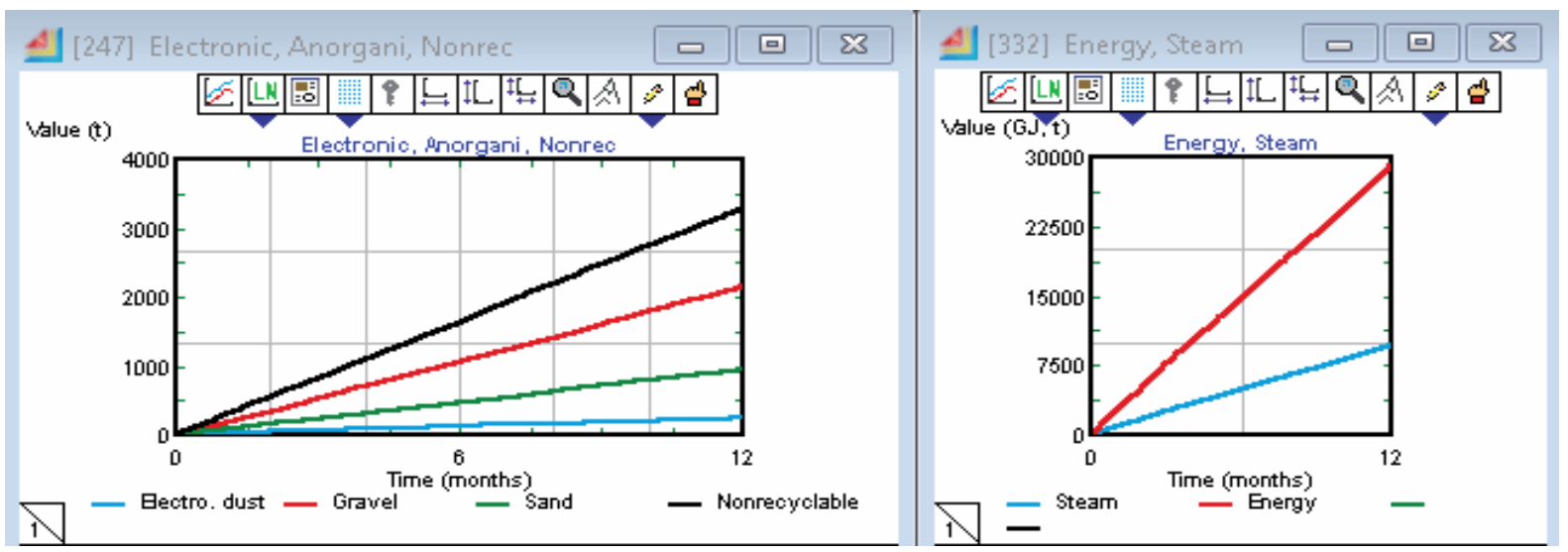

Fig. 3. Production of recycled electro, inorganic, and non- recyclable waste from the separated waste, and steam and energy from the incineration of non-recyclable waste in a one-year period. 
- The third concerns the processing of the resulting charred mass and focus is on outstanding amounts of metals in the resulting burn.

Of the total amount of municipal waste is directly separable $10 \%$ plastics. Department for plastic processing is used for treatment of plastic packaging and plastic waste through re-granulation in the form of plastic granules, which will serve as starting material for the production of new plastic products. Sift clean plastic scrap sequentially through the stack of plastic waste shredder for plastic, plastic cleaner, plastic drying, and granulation of plastics department to output the finished granulate. In general, per ton of the plastic granulate should be 1.2 tons of waste plastics thus saving 2.5 tons of oil, which would be needed for production. Recycling old plastic can save up to $97 \%$ less energy than the production of plastics from petroleum.

Most of the available energy of biogas generated in biogas plants is contained in the component methane $\left(\mathrm{CH}_{4}\right)$. Methane contained in biogas is typically between $45-72 \%$ and varies even in a relatively steady state of technology. Biogas further comprises carbon dioxide $\left(\mathrm{CO}_{2}\right)$, silicon $(\mathrm{Si})$, nitrogen $\left(\mathrm{N}_{2}\right)$, a small amount of sulfur (S), and other impurities. The presence of $\mathrm{CO}_{2}$ in biogas is beneficial because $\mathrm{CO}_{2}$ acts as an anti-knock.

Recycling old paper, you can save up to $75 \%$ of the electricity used compared to primary production of paper, which means that the processing of one ton of old paper will save 500-600 kWh of electricity. One ton of old waste paper can replace up to $2.5 \mathrm{~m}^{2}$ of extracted timber. Recycling paper reduces water consumption compared to primary production up by $58 \%$. To recycle 1 ton of paper can save up to $40 \mathrm{~m}^{3}$ of water.

\section{Environmental Assessment Based on Logistics, Statistics, and Simulation}

After setting the simulation model, follows its use for the study of total separation and recycling activities. The advantage of the computer simulations approach is the fact that it enables us to examine the conditions that would not be possible in reality, considering the safety of company workers as well as designing systems. The simulation mimics the actual operation of the system for a period of one year, which is 8760 hours. The input of one element in the system represents the arrival of one ton of waste into the separation and recycling process.

Results of simulation show that by total separation and waste recycling in the frame of concrete region it is possible to produce during one year (Figs 1-3) approximately 9,000 tons of plastic granulates, 39,000 $\mathrm{m}^{3}$ of fertilizer by the way of digestate, approximately 3.9 million $\mathrm{m}^{3}$ of biogas, 7,700 tons of recycling paper, possibility to recycle 2,400 tons of multilayer packages, 8,000 tons of glass, 3,000 tons of old textile, approximately 3,500 tons of iron, 1,500 tons of non-ferrous metals, to produce around 2,700 wooden pellets, 1,200 tons of gum granulate, to process around 800 tons of dangerous waste, to process around
2,400 tons of electro waste, approximately 2,100 tons of gravel and 940 tons of sand and to liquidate around 3,200 tons of non-recyclable waste. No recyclable waste is liquidated by combustion. By combustion of 3,200 tons of non-recyclable waste there is released energy approximately 29,000 GJ, around 9,500 tons of water vapour, and 8 tons emissions, where only 0.2 milligrams present dioxin.

From the previous research results that Slovakia belongs among EU states that recycle waste the least. Waste end at dumps and partially they are combusted in incinerators. Data used in the simulation model are from research of the incinerator near Košice. Pressure and demands of the European Union require the system in Slovakia to be more consequent and more orientated to the recycling and secondary evaluation of waste. Due to the mentioned the research had a goal to suggest system for total separation and waste recycling. To suggest such system and its verification can be done preferably by simulation.

From the view of material and energetic evaluation of waste it is necessary to follow the volume of elaborated and recycled waste, for example by using time series analysis, the goal of which is mostly the construction of a correspondent model. Analysis of the model enables us mainly to understand the mechanism of data rising, according to which it is possible to find out, for example, seasonal behaviour of imported waste volume. Seasonal influences are caused by direct or indirect reasons. The seasonal element has its origin in four seasons' rotation.

Table 1. Pearson correlation coefficients and the theoretical expression.

\begin{tabular}{|c|c|c|}
\hline \multicolumn{3}{|c|}{ Waste supply } \\
\hline Pearson correlation coefficient & Theoretical modes \\
\hline Plastics granules & 0,091 & $\mathrm{y}=0,0488 \mathrm{x}+427,83$ \\
\hline Biogas & 0,468 & $\mathrm{y}=67,177 \mathrm{x}-98184$ \\
\hline Digestate & 0,807 & $\mathrm{y}=1,5752 \mathrm{x}-7041$ \\
\hline Paper & $-0,014$ & $\mathrm{y}=-0,0044 \mathrm{x}+674,97$ \\
\hline Glass & $-0,003$ & $\mathrm{y}=-0,0017 \mathrm{x}+683,36$ \\
\hline Textile & 0,005 & $\mathrm{y}=0,0017 \mathrm{x}+259,31$ \\
\hline Iron & 0,069 & $\mathrm{y}=0,0214 \mathrm{x}+149,93$ \\
\hline Nonferrous material & $-0,205$ & $\mathrm{y}=-0,0471 \mathrm{x}+440,62$ \\
\hline Wood pellets & 0,083 & $\mathrm{y}=0,0278 \mathrm{x}+44,737$ \\
\hline Rubber granules & $-0,214$ & $\mathrm{y}=-0,0409 \mathrm{x}+374,66$ \\
\hline Dangerous waste & $-0,038$ & $\mathrm{y}=-0,0066 \mathrm{x}+112,23$ \\
\hline Electronic dust & $-0,137$ & $\mathrm{y}=-0,0135 \mathrm{x}+111,15$ \\
\hline Gravel & $-0,098$ & $\mathrm{y}=-0,0271 \mathrm{x}+366,62$ \\
\hline Sand & 0,083 & $\mathrm{y}=0,0165 \mathrm{x}-32,723$ \\
\hline No recyclable & $-0,067$ & $\mathrm{y}=-0,0206 \mathrm{x}+406,35$ \\
\hline
\end{tabular}


Understanding the model enables us to predict future development of the system.

The relationship among volumes of imported waste $\{x i\}$ and volume of separated materials $\{y i\}$ express theoretical models (Table 1).

Their importance is given also by Pearson coefficient of correlation for individual separated elements. Resulting values of correlation coefficients (Table 1) prove that among several analysed items there is very strong linear dependence - with growth of imported waste also values of produced digestate volume is directly and proportionally growing. Among some items there is only a slight dependence, for example biogas, partially also non-ferrous waste and rubber and among some there is weak dependence, for example glass, textile, etc.

Interesting facts results from the analysis of simulation results by the application of time series analysis (Figs 4-5). The volume of produced biogas and digestate is changing in accord with quality of input biomass, which is proven also by big dispersion

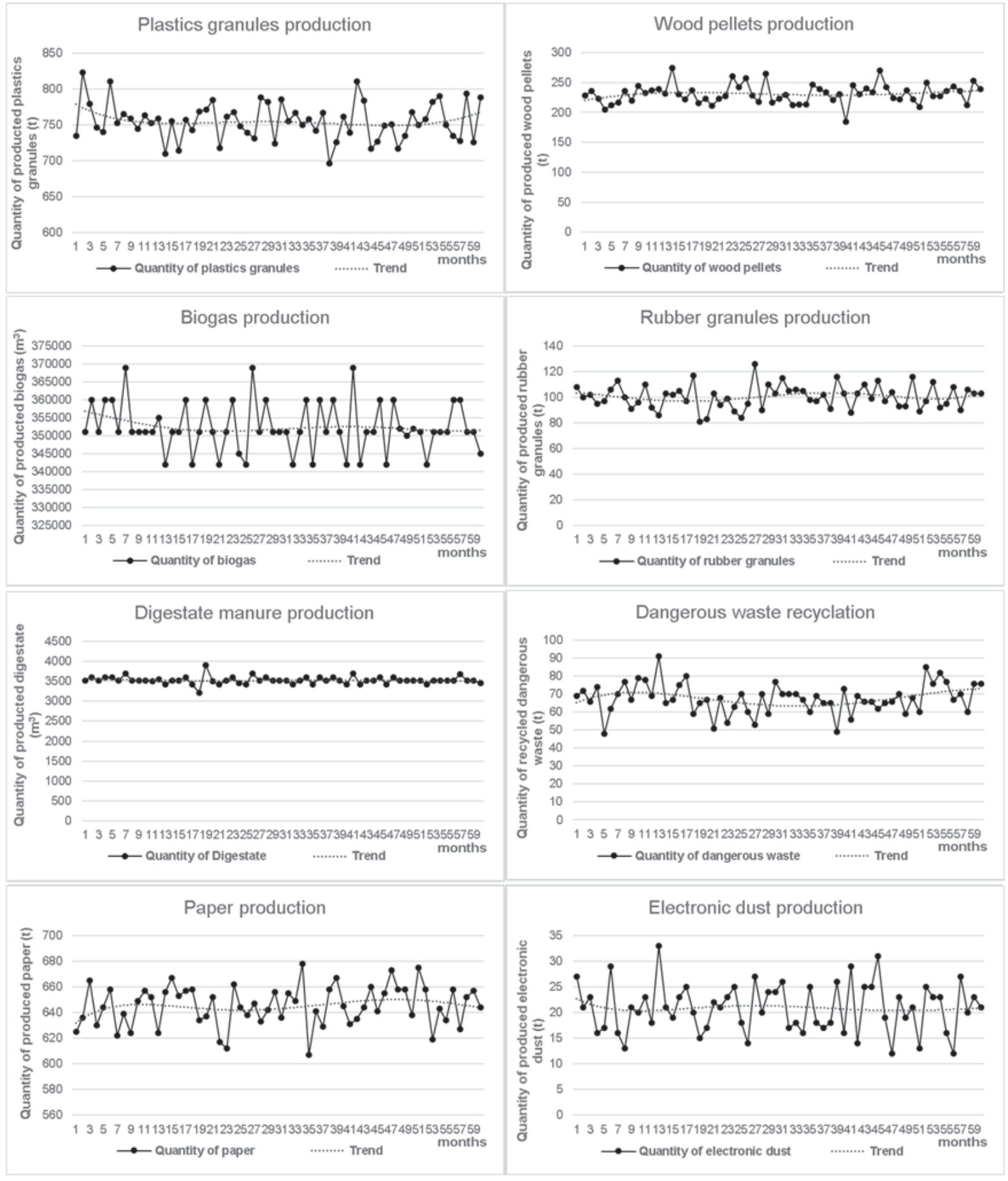

Fig. 4. Analysis of seasonal element of separated wastes I. 


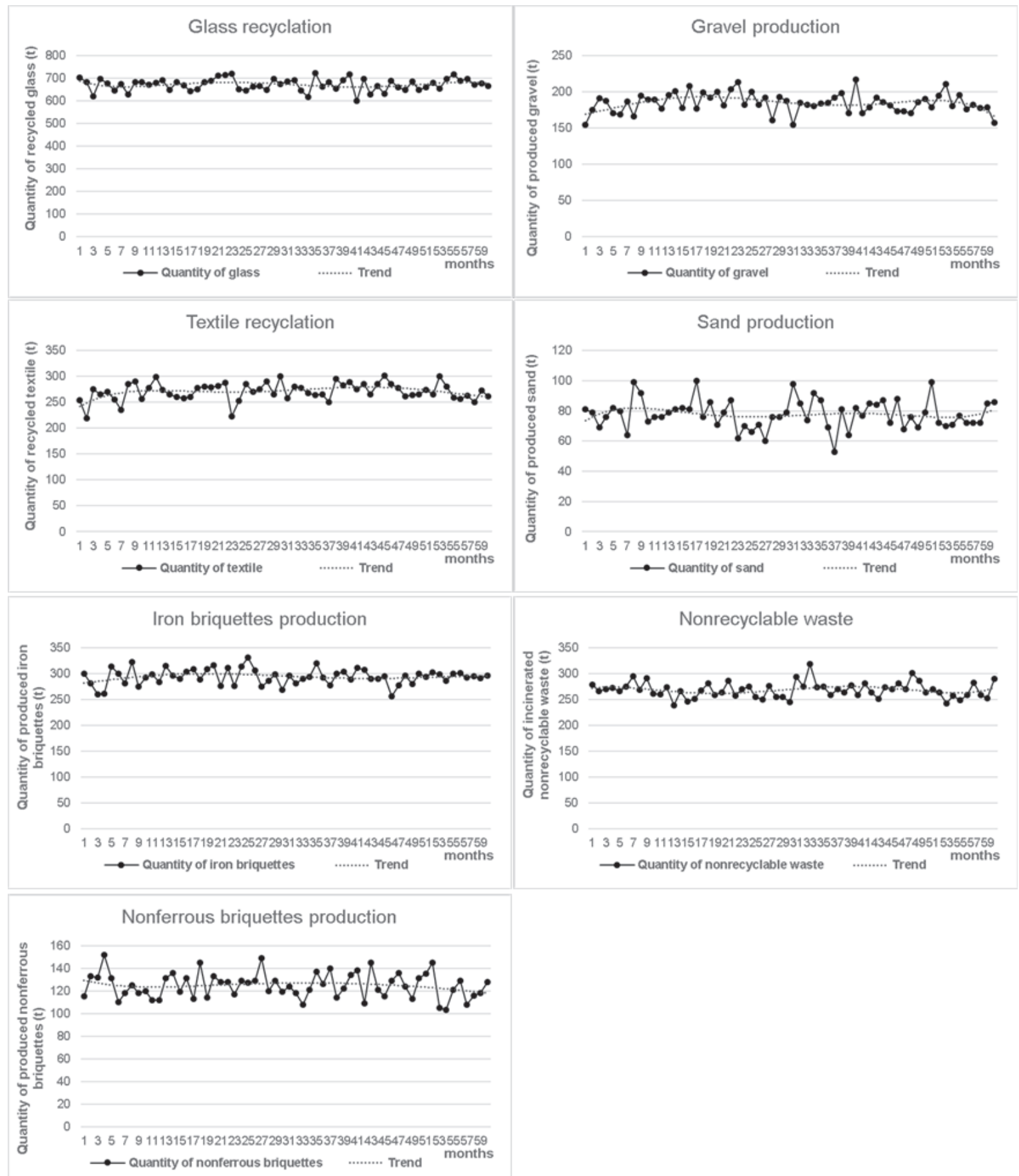

Fig. 5. Analysis of seasonal element of separated wastes II.

of produced biogas and small dispersion of digestate production for fertilizers. Certain biomass as an input material for biogas production is more qualitative at the same volume than others, which means from a given volume there is produced more or less biogas, while the volume of digestate for fertilizers is dosed equally. Due to the mentioned production of biogas being uneven with considerable dispersions, which exists also in practice, and production of fertilizer digestate is steady as for the volume, since the volume of digestate production depends only on the volume of biomass dosage.
From the simulation results that suggested a complex system of waste recycling in the frame of searched region is able to process yearly production of communal waste. From the economical view waste combustion per sold energy brings more than $€ 6$ million per year. In comparing with prices from the sale of basic raw materials from total waste recycling it would be possible to obtain $€ 9.3$ million per year (Table 2).

The findings indicate that many of the input waste components can be recycled without the need for actual incineration. This activity is highly dependent 
Table 2. Prices of raw materials produced by total recycling in a one-year period.

\begin{tabular}{|c|c|c|c|c|c|c|c|c|}
\hline \multirow[b]{2}{*}{ Plastics granules } & \multicolumn{2}{|c|}{ Volume/year } & \multicolumn{2}{|c|}{ Price } & \multicolumn{2}{|c|}{ Price } & \multicolumn{2}{|c|}{ Total price/year } \\
\hline & 9000 & $\mathrm{t}$ & 0.70 & eur $/ \mathrm{kg}$ & 700.00 & eur/t & 6300000.00 & eur \\
\hline Digestate manure & 39000 & $\mathrm{t}$ & 5.50 & $\mathrm{eur} / \mathrm{t}$ & 5.50 & eur/t & 214500.00 & eur \\
\hline Biogas & 390000 & $\mathrm{~m}^{3}$ & 0.29 & $\mathrm{eur} / \mathrm{m}^{3}$ & 0.29 & $\mathrm{eur} / \mathrm{m}^{3}$ & 113100.00 & eur \\
\hline Paper & 7700 & $\mathrm{t}$ & 0.05 & eur $/ \mathrm{kg}$ & 50.00 & $\mathrm{eur} / \mathrm{t}$ & 385000.00 & eur \\
\hline Multilayer materials & 2400 & $\mathrm{t}$ & \multicolumn{6}{|c|}{ Processing in workplaces plastics. paper. metals } \\
\hline Glass & 8000 & $\mathrm{t}$ & 0.03 & eur $/ \mathrm{kg}$ & 30.00 & eur/t & 240000.00 & eur \\
\hline Textile & 3000 & $\mathrm{t}$ & 0.02 & eur/kg & 20.00 & eur/t & 60000.00 & eur \\
\hline Iron briquettes & 3500 & $\mathrm{t}$ & 0.10 & eur $/ \mathrm{kg}$ & 100.00 & eur/t & 350000.00 & eur \\
\hline Nonferrous briquettes & 1500 & $\mathrm{t}$ & 0.70 & eur $/ \mathrm{kg}$ & 700.00 & eur/t & 1050000.00 & eur \\
\hline Wood pellets & 2700 & $\mathrm{t}$ & 0.10 & eur $/ \mathrm{kg}$ & 100.00 & eur/t & 270000.00 & eur \\
\hline Rubber granules & 1200 & $\mathrm{t}$ & 0.05 & eur $/ \mathrm{kg}$ & 50.00 & eur/t & 60000.00 & eur \\
\hline Dangerous waste* & 800 & $\mathrm{t}$ & 0.16 & eur $/ \mathrm{kg}$ & 160.00 & eur/t & -128000.00 & eur \\
\hline Electronic waste & 2400 & $\mathrm{t}$ & \multicolumn{6}{|c|}{ Processing in workplaces plastics. metals } \\
\hline Gravel & 2100 & $\mathrm{t}$ & 4.00 & $\mathrm{eur} / \mathrm{t}$ & 4.00 & $\mathrm{eur} / \mathrm{t}$ & 8400.00 & eur \\
\hline Sand & 940 & $\mathrm{t}$ & 4.00 & eur/t & 4.00 & $\mathrm{eur} / \mathrm{t}$ & 3760.00 & eur \\
\hline No recyclable waste & 3200 & $\mathrm{t}$ & \multicolumn{6}{|c|}{ Counted as price after incineration } \\
\hline Energy after incineration & 29000 & GJ & 14.40 & eur/GJ & 14.40 & eur/GJ & 417600.00 & eur \\
\hline Gas for incineration* & 339200 & $\mathrm{~m}^{3}$ & 0.29 & $\mathrm{eur} / \mathrm{m}^{3}$ & 0.29 & $\mathrm{eur} / \mathrm{m}^{3}$ & -98368.00 & eur \\
\hline & & & & & \multicolumn{2}{|c|}{ TOTAL SUM } & 9344360.00 & eur \\
\hline
\end{tabular}

* costs of company

on intensive logistical activities and on the interest of other waste-processing companies to accept separated materials. Generally, it is possible to present the overall simulation model of the entire waste processing and total recycling waste (Fig. 6).

\section{Results, Discussion, and Conclusions}

An essential step in waste reduction is the use of green materials as well as its secondary recovery, starting with the separation of waste. The volume of communal waste stored at stocks and coming back to the environment presents no ecologically dangerous material, mainly in the case of plastic waste, metals, various chemical materials, etc. In the case of waste incineration, mainly products from oil, one type of dangerous waste is changing to other type of dangerous material, which part is immediately returning during the process of burning to air, and other parts must be stored by the way of dangerous slag due to the ecology. Just due to the mentioned liquidation of waste by total separation and recycling is more convenient then incineration.

It is necessarily aware that without logistics it would not be possible to manage growing volumes of waste in any place in the world. In a given case there is either external or internal logistics. External logistics solves the allocation of collection places and companies for waste processing, the system and structure of waste collection, providing cooperation among individual elements that create a chain for waste processing. Internal logistics has a goal to provide realization of processes that change directly the character and characteristics of waste, which means waste as a secondary raw material, which is possible to transform to the way in which character of the waste is lost and becoming as basic raw material for further production and use. Only qualitative coordination of external as well as internal logistics is able to provide rapid, proper, and qualitative elaboration of produced waste.

But due to the future research following question remain:

- By what way to provide financial coverage for building complexes for total waste recycling?

- Is existing legislation sufficient to provide serious and proper waste sorting?

\section{Acknowledgements}

The submitted paper is a part of the project "Implementation of new methods and forms of 
education based on applied research in the field of study 8.5.1 Logistics" KEGA 056TUKE-4/2018, funded by the Slovak Cultural and Education Grant Agency.

\section{Conflict of Interest}

The authors declare no conflict of interest.

\section{References}

1. BROOKS R., CETIN M. Application of construction demolition waste for improving performance of subgrade and subbase layers. International Journal of Research and Reviews in Applied Sciences, 12 (3), 375, 2012.

2. CETIN M. Chapter 55: Using Recycling Materials for Sustainable Landscape Planning. ST. Kliment Ohridski University Press, SOFIA. Book: Environment and Ecology at the Beginning of $21^{\text {st }}$ Century, Eds: Recep Efe, Carmen Bizzarri, İsa Cürebal, Gulnara N. Nyusupova, 783, 2015.

3. CETIN M. Consideration of permeable pavement in landscape architecture. Journal of Environmental Protection and Ecology, 16 (1), 385, 2015.

4. CETIN M. Landscape Engineering, Protecting Soil, and Runoff Storm Water, Advances in Landscape Architecture, Dr. Murat Ozyavuz (Ed.), InTech, 2013.

5. CETIN M. Pavement design with porous asphalt, Temple University, Ph.D. Thesis, Philadelphia, USA, 2013.

6. KOVÁCS G. Logistics and production processes today and tomorrow. Acta logistica, 3 (4), 1, 2016.

7. SHEU J.B. Green supply chain management, reverse logistics and nuclear power generation. Transportation Research, Part E: Logistics and Transportation Review, 44 (1), 19, 2008

8. POKHAREL S., MUTHA A. Perspectives in reverse logistics: a review. Resources, Conservation and Recycling, 53 (4), 175, 2009.

9. ABDESSALEM M., HADJ-ALOUANE A.B., RIOPEL D. Decision modelling of reverse logistics systems: selection of recovery operations for end-of-life products. International Journal of Logistics Systems and Management, 13 (2), 139, 2012.

10. CAO S., ZHANG K. Optimization of the flow distribution of e-waste reverse logistics network based on NSGA II and TOPSIS. International Conference on E-Business and E-Government (ICEE 2011), 1, 2011.

11. ZHANG K.J., WEI S.S. Comparison of Overseas E-waste Recycling Systems and Their Enlightment to China. China Population Resources and Environment, 2009 (2), 109, 2009.

12. STRAKA M. The position of distribution logistics in the logistic system of an enterprise. Acta logistica, 4 (2), 23, 2017.

13. POHLEN T.L., FARRIS M.T. Reverse Logistics in Plastics Recycling. International Journal of Physical Distribution \& Logistics Management, 22 (7), 35, 1992.

14. TISCHER A., BESIOU M., GRAUBNER C.A. Efficient waste management in construction logistics: a refurbishment case study. Logistics Research, 6 (4), 159, 2013.

15. DIAZ R., OTOMA S. Cost-benefit analysis of waste reduction in developing countries: a simulation. Journal of Material Cycles Waste Management, 16 (1), 108, 2014.
16. ROSOVÁ A., KAČMÁRY P., FABIÁNOVÁ J. The methodologies for inventory analysis in the logistic chain of an enterprise. Acta logistica, 1 (4), 29, 2014.

17. WANG W. A Decision Method for Returns Logistics Based on the Customer's Behaviour in E-commerce, Procedia Computer Science, 60 (2015), 1506, 2015.

18. TALINLI I., TOPUZ E., AYDIN E. Waste management alternatives for hazardous waste lists. European Water, 53 (2016), 37, 2016.

19. YAO L., HE W., LI G., HUANG J. The integrated design and optimization of a WEEE collection network in Shanghai, China. Waste Management \& Research, 31 (9), 910, 2013.

20. BÁRTOVÁ P., HUSÁKOVÁ N. Reverse logistics and its variations, LOGI 2010, 370, 2010.

21. ZHANG Y.M., HUANG G.H., HE L. An inexact reverse logistics model for municipal solid waste management systems. Journal of Environmental Management, 92 (3), 522, 2011.

22. FLEISCHMANN M., BLOEMHOF-RUWAARD J.M., DEKKER R., VAN DER LAAN E., VAN NUNEN J.A.E.E., VAN WASSENHOVE L.N. Quantitative models for reverse logistics: A review, European Journal of Operational Research, 103 (1), 1, 1997.

23. KAZEMZADEHA N., HU G. Optimization models for biorefinery supply chain network design under uncertainty. Journal of Renewable and Sustainable Energy, 5 (5), 1, 2013.

24. IAKOVOU E., KARAGIANNIDIS A., VLACHOS D., TOKA A., MALAMAKIS A. Waste biomass-to-energy supply chain management: A critical synthesis. Waste Management, 30 (10), 1860, 2010.

25. STRAKA M., TREBUNA P., MALINDZAKOVA M., ROSOVA A., POPOVIC R., FILL M. Logistics and chemical technology as effective means for the collection and treatment of biodegradable wastes. Przemysl chemiczny, 95 (8), 1549, 2016.

26. AKDOĞAN M.S., COŞKUN A. Drivers of Reverse Logistics Activities: An Empirical Investigation. Procedia - Social and Behavioral Sciences, 58 (2012), 1640, 2012.

27. MAŁKUS T. Assumptions of trust in logistics cooperation, Acta logistica, 4 (3), 1, 2017.

28. TAN S.T., LEE CH.T., HASHIM H, HO W.S., LIM J.S. Optimal process network for municipal solid waste management in Iskandar Malaysia. Journal of Cleaner Production, 71, 48, 2014.

29. CHANG Y.H., CHANG N.B. Optimization analysis for the development of short-team solid waste management strategies using presorting process prior to incinerators. Resoures, Conservation and Recycling, 24 (1), 7, 1998.

30. CHANG Y-J., LIN M-D. Compromising economic cost and air pollutant emissions of municipal solid waste management strategies by fuzzy multiobjective optimization model. Journal of the Air \& Waste Management Association, 63 (6), 712, 2013.

31. MÜNSTER M., RAVN H., HEDEGAARD K., JUUL N., LJUNGGREN SÖDERMAN M. Economic and environmental optimization of waste treatment. Waste Management, 38 (2015), 486, 2015.

32. RATHI S. Optimization model for integrated municipal solid waste management in Mumbai, India. Environment and Development Economics, 12 (1), 105, 2007.

33. RODIONOV M., NAKATA T. Design of an optimal waste utilization system: a case study in St. Petersburg, Russia. Sustainability, 3 (9), 1486, 2011. 
34. AKBARPOUR SHIRAZI M., SAMIEIFARD R., ABDULI M.A., OMIDVAR B. Mathematical modeling in municipal solid waste management: case study of Tehran. Journal of Environmental Health Science and Engineering, 14 (8), 2016.

35. WITKOWSKI K., HUK K., PERZYŃSKA A. Selected IT solutions in logistics strategies of supply chains, Acta logistica, 3 (4), 31, 2016.

36. STRAKA M., MALINDŽÁKOVÁ M., TREBUŇA P., ROSOVÁ A., PEKARČÍKOVÁ M., FILL M. Application of EXTENDSIM for improvement of production logistics' efficiency. International Journal of Simulation Modelling, 16 (3), 422, 2017.

37. LANER D. The consideration of long-term emissions from landfills within life-cycle assessment. Waste Management \& Research, 27 (5), 463, 2009.

38. YANG Y.B., RYU C., GOODFELLOW J., NASSERZADEH SHARIFI V., SWITHENBANK J.
Modelling Waste Incineration in Grate Furnaces, Process Safety and Environmental Protection, 82 (3), 208, 2004.

39. LUO C., MAHOWALD N., BOND T., CHUANG P.Y., ARTAXO P., SIEFERT R., CHEN Y., SCHAUER J. Incineration iron distribution and deposition. Global Biogeochemical Cycles, 22 (1), GB1012, 2008.

40. YEOMANS J.S., HUANG G.H., YOOGALINGAM R. Combining Simulation with Evolutionary Algorithms for Optimal Planning Under Uncertainty: An Application to Municipal Solid Waste Management Planning in the Regional Municipality of Hamilton-Wentworth. Journal of Environmental Informatics, 2 (1), 11, 2003.

41. RYU C., YANG Y.B., NASSERZADEH V., SWITHENBANK J. Thermal reaction modeling of a large municipal solid waste incinerator. Incineration Science and Technology, 176 (11), 1891, 2004. 
